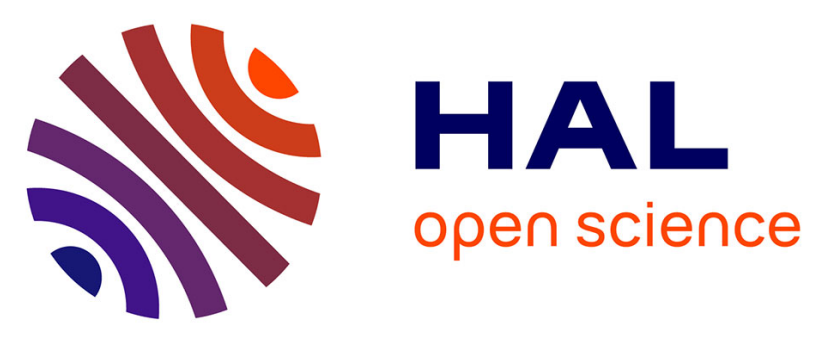

\title{
Degassing at La Soufrière de Guadeloupe volcano (Lesser Antilles) since the last eruptive crisis in 1975-77: Result of a shallow magma intrusion?

\author{
Marie Boichu, Benoît Villemant, Georges Boudon
}

\section{To cite this version:}

Marie Boichu, Benoît Villemant, Georges Boudon. Degassing at La Soufrière de Guadeloupe volcano (Lesser Antilles) since the last eruptive crisis in 1975-77: Result of a shallow magma intrusion?. Journal of Volcanology and Geothermal Research, 2011, 203, pp.102-112. 10.1016/j.jvolgeores.2011.04.007 . hal-01163215

\section{HAL Id: hal-01163215 \\ https://hal.science/hal-01163215}

Submitted on 16 Jun 2015

HAL is a multi-disciplinary open access archive for the deposit and dissemination of scientific research documents, whether they are published or not. The documents may come from teaching and research institutions in France or abroad, or from public or private research centers.
L'archive ouverte pluridisciplinaire HAL, est destinée au dépôt et à la diffusion de documents scientifiques de niveau recherche, publiés ou non, émanant des établissements d'enseignement et de recherche français ou étrangers, des laboratoires publics ou privés. 


\title{
Degassing at La Soufrière de Guadeloupe volcano (Lesser Antilles) since the last eruptive crisis in 1975-77: Result of a shallow magma intrusion?
}

\author{
Marie Boichu ${ }^{\text {a,b, }}$, Benoît Villemant ${ }^{\text {b,c,d }}$, Georges Boudon ${ }^{\text {b,c }}$ \\ a Department of Geography, University of Cambridge, Downing Place, Cambridge CB2 3EN, United Kingdom \\ b Équipe de Géologie des Systèmes Volcaniques, Institut de Physique du Globe de Paris, Sorbonne Paris Cité, Sorbonne Paris CitÃl', Paris 75005, France \\ c CNRS (UMR 7154), France \\ ${ }^{\mathrm{d}}$ Université Pierre et Marie Curie, UFR 918, CNRS UMR 7193, France
}

Corresponding author now at: Institut Pierre Simon Laplace, Laboratoire de Météorologie Dynamique, École Polytechnique, 91128 Palaiseau cedex, France. Tel.: +33 169335171; fax: +33 169335108. E-mail address: mboichu@Imd.polytechnique.fr (M. Boichu).

article info

Article history:

Received 24 September 2010

Accepted 11 April 2011

Available online 17 April 2011

\section{Keywords:}

Episodic volcanic degassing

La Soufrière de Guadeloupe

magma intrusion

thermal springs

hydrothermal system

sealing processes

\section{a b s tract}

In the 15 years following the last crisis of phreatic type in 1975-77, the hydrothermal and seismic activity of La Soufrière de Guadeloupe has displayed an episodic behavior superimposed on a long-term decay, as inferred from seismicity and degassing, monitored through fumarolic emissions and $\mathrm{Cl}$ content in thermal springs. In particular, the evolution of the $\mathrm{Cl}$ content can be explained by a succession of magmatic gas injections into the hydrothermal system. This episodic supply of gas may be associated to the thermodynamic evolution of a batch of magma intruded at shallow depth around 1976. Progressive magma cooling, crystallization, gas exsolution and pressure buildup lead to cyclic failure of host rock around the intrusion, and episodic release of gas, with a decreasing frequency as cooling proceeds. This physical model allows to reproduce the pattern of degassing activity of La Soufrière, including the decreasing frequency of $\mathrm{Cl}$ pulses with time. Our preferred forward model of $\mathrm{Cl}$ pulses involves a magma intrusion volume in the range $0.01-0.52 \mathrm{~km}^{3}$ and a tensile strength of the surrounding rock in the range 0.1-0.6 MPa. These results reinforce the hypothesis of a shallow magma intrusion triggering the 1975-77 crisis and provide an explanation for the degassing and seismic activities observed until 1992. 


\section{Introduction}

La Soufrière volcano (also known as La Grande Découverte-Soufrière) is located in Basse-Terre, the western part of Guadeloupe island, and part of the inner volcanic arc of the Lesser Antilles (Fig. 1A). Its last magmatic eruption took place around 1530 A.D. in the Amic crater, a horseshoe-shaped depression inherited from a flank collapse in 3100 years B.P., and produced the current lave dome of La Soufrière (Boudon et al., 1989, 2008) (Fig. 1B). Since then, phreatic crises occurred in 1690, 1797-98, 1812, 1836-37, 1956 and 1976-77 (Jolivet, 1958; Barrabé and Jolivet, 1958; Feuillard et al., 1983; Komorowski et al., 2005). The most important, in terms of magnitude and duration, are those of 1797-98 and 1975-77. The 1975-77 crisis was characterized by an increase in seismicity since July 1975 with a peak of seismic activity in August 1976, and 26 phreatic explosions between July 1976 and April 1977 (Feuillard et al., 1983). La Soufrière volcano then returned to a quiet state.

Different interpretations have been put forward to explain the 1975-77 activity, invoking either a magmatic or hydrothermal origin. On one hand, Feuillard et al. (1983) suggested 'a stillborn' (according to their own words) or 'failed' magmatic eruption (Moran et al., 2011) in 1976. They argued that significant overpressure in the magma chamber was abruptly released at either a critical stage of magma differentiation or as a consequence of input of further magma from beneath. This fractured the host rocks, opening a path to the surface to discharge hot gases and generate phreatic explosions. The energy supplied by the magma chamber was thought to have been buffered by the hydrothermal system, impeding a magmatic eruption. Alternatively, Zlotnicki et al. (1992) favored a hydrothermal expla-nation. They propose that the recurrence of the two last phreatic eruptions of La Soufrière was the result of constant heat transfer from a deep magma to surficial aquifers, the latter being regulated by cycles of clogging and reopening of a fracture system.

Since 1978, La Soufrière has been intensively monitored. A three decade record of geophysical and geochemical data is now available representing one of the most sustained time-series available for any volcano (Rapports de l'Observatoire Volcanologique et Sismologique de Guadeloupe, 1976-2006). In particular, information gathered on seismic and degassing activities following the crisis, shed new light on these questions. Both seismicity and degassing, which is monitored via observations of fumaroles and of water chlorine content of thermal springs, show a similar slow decrease in the 15 years following the crisis. Superimposed on this secular trend are episodic perturbations. These appear as peaks in seismicity (Fig. 2A). In the water $\mathrm{Cl}$ content of the thermal spring located at closest distance from the lava dome (Carbet Échelle), the occurrence of brief pulses also attests of an episodic behavior (Fig. 2B). This episodicity seen in the water chemistry ceased around 1992, when seismic and fumarolic activities had reached a low level. Since 1992, the renewal of seismic and fumarolic activities suggests the onset of a phase of unrest (Figs. 2 and 4). With the appearance of strong acid emissions in the summit zone in 1998, the Observatoire Volcanologique et Sismologique de Guadeloupe (Institut de Physique du Globe de Paris) raised the volcano alert level to one of 'vigilance'.

A similar episodic degassing has been observed at other volcanoes (e.g. Phlegrean Fields (Chiodini et al., 2003), Galeras (Fischer et al., 1996)). What is the phenomenon triggering such an episodic behavior? Various processes occurring at different depths in the magmatic and hydrother-mal system have been proposed to explain fluctuations of the gas flux or composition measured either in plumes, fumaroles or in thermal springs. A series of distinct degassing events may be generated by magma rise in discontinuous separate events (Nuccio and Paonita, 2001). Alternatively, enhanced by the heat dissipated from a nearby magma batch, processes of hydrofracturing (Rowe et al., 1992), thermal cracking or sealing (Edmonds et al., 2003; Ohba et al., 2008) may lead to episodic release of magmatic fluids. During gas transfer to the surface, variations of the permeability of the hydrothermal system, often due to surficial sealing processes, may also occur (Zlotnicki et al., 1992; Fischer et al., 1994; Harris and Maciejewski, 2000; Christenson et al., 2010). Another possibility suggested by thermochemical models is that decompression, cooling, oxidation, and interaction with wall rocks and with the hydrothermal system can lead to widely varying plume composition and flux (Giggenbach and Sheppard, 1989; Symonds et al., 2001). The proportion of volatile components in surface waters may also be modified by the dynamics of the aquifers reflecting external influences, such as seasonal supply of meteoric water (Ingebritsen et al., 2001; López et al., 2006). And lastly, in a water-saturated porous medium heated by a substantial heat flux from beneath, convective and gravitational instabilities can emerge, triggering oscillations in the thermal field and a cyclic ascent of hydrothermal fluids (Vandemeulebrouck et al., 2005, 2008).

At La Soufrière volcano, using a model for the transport of magmatic gases by water flow in a porous medium, Villemant et al. (2005) showed that the evolution of $\mathrm{Cl}$ content in thermal springs may result from the episodic injection of magmatic gas pulses into the hydrothermal system. Boichu et al. (2008) suggested that the thermodynamic evolution of a magma intrusion may fuel this episodic degassing, spanning timescales from years to decades. Due to the thermal contrast with the host rocks, a magma stored at shallow depth cools, crystallizes and exsolves volatiles. When the resulting magma overpressure exceeds a critical threshold, wall rocks of the reservoir are fractured and gas escapes. The intrusion then returns to lithostatic pressure and a new cooling-crystallization-degassing cycle starts. This physical model also describes the existence of two regimes of degassing under specific conditions: an early phase with frequent expulsions of gas and a later phase with a lower gas pulse frequency. As we show in Section 3, $\mathrm{Cl}$ content in thermal springs of La Soufrière exhibits a similar change of regime. For this reason, we propose here to explore the hypothesis that a shallow magma intrusion at La Soufrière occurred around 1976. We investigate whether the degassing pattern of this volcano may be reproduced by the model of Boichu et al. (2008), and discuss the implications for understanding the magmatic system of La Soufrière. Finally, we propose an interpretation of the activity of La Soufrière since the 1975-77 crisis leading to the reactivation of seismic and fumarolic activities in 1992.

\section{Volcanic activity since 1976}

\subsection{Thermal spring chemistry}

Amplified by the tropical climate and strong rainfall (up to $10 \mathrm{~m} / \mathrm{year}$ at the summit), La Soufrière hosts a large permanent hydrothermal system with intermittent fumarolic activity and many thermal springs spread all over the Grande Découverte volcanic complex (Fig. 1). An exceptional physicochemical survey of six thermal springs has been carried out over the past decades. It began two years after the end of the last crisis, in 1979, with a high sampling frequency $(\sim 1-4 /$ month). Thermal spring distribution is controlled by geological structures inherited from successive partial destruction of the edifice (i.e. the caldera of La Grande Découverte and the rims of Carmichael and Amic horseshoe-shaped craters). Major elements and halogen species in the water show that the six thermal springs can be divided according to whether or not they are contaminated by magmatic fluids or by seawaterderived brines (Bigot and Hammouya, 1987; Brombach et al., 2000; Villemant et al., 2005). The study of chlorine and bromine contents of the springs contaminated by magmatic fluids, including Carbet Échelle, Bains Jaunes, Galion and Chutes du Carbet (Fig. 1B), yields information on magma degassing (Villemant et al., 2005). Indeed, halogen species are tracers of magmatic water with conservative transfer from a shallow magma to the hydrothermal system. The high partition coefficient of these elements between the magmatic melt and the vapor phase implies their large transfer to the fluid phase. They are expelled from andesitic melts with $\mathrm{H}_{2} \mathrm{O}$ degassing in the form of acids $(\mathrm{HCl}, \mathrm{HBr})$. These acids are stable in water vapor because they are little affected by processes of cooling, decompression, mixing with air and interaction with surrounding rocks. When these ascending magmatic fluids meet an aquifer, the high solubility of halogen acids in water leads to their almost complete dissolution in groundwaters. In this state, they interact neither with rocks nor with other solvated ions.

Different temporal evolutions of the water chlorine content are observed, depending on the distance of the considered thermal spring from the summit of the lava dome (Fig. 3). Carbet Échelle, the closest spring from the summit, displays a secular trend with ephemeral fluctuations in chlorine (Figs. 2B and 3). A significant mean $\mathrm{Cl}$ content (of $\sim 300 \mathrm{ppm}$ ) is observed since 1979 , with a slow decrease from 1982 until around 1992. Superimposed on this secular trend are high-frequency $\mathrm{Cl}$ pulses with various amplitude and spacing. Large magnitude pulses occurred until 1990. In the following years, low variations 
of the chlorine content are observed. By contrast, the $\mathrm{Cl}$ content at Chutes du Carbet (the furthest spring from the summit) shows a smoother response, with a single maximum delayed in time with respect to the starting date of the crisis. Bains Jaunes and Galion show an intermediate state. This behavior of thermal springs is interpreted as a delayed record of a succession of discrete magmatic gas pulses which have been advected and dispersed during their transfer through the hydrothermal system (Villemant et al., 2005).

\subsection{Fumarolic activity}

During the last phreatic crisis, there were 26 explosions between July 1976 and March 1977 emitting $\mathrm{H}_{2}$ S-rich vapor plumes and sustained fumarolic activity (Zlotnicki et al., 1992; Komorowski et al., 2005). Fumarolic activity was focused at the summit (Fente du Nord, Gouffre Tarissan, Gouffre Dupuy and Cratère Sud), on the flanks (Lacroix fumaroles, 8 July 1976 and 30 August 1976 faults) and at the base of the lava dome (fumaroles Colardeau, Chaudières-Souffleur, Carbet Échelle and Morne Mitan) (Fig. 1C). This activity decreased after May 1977, progressively leaving the summit zone, migrating to the lava dome periphery, and almost vanishing in 1984. Between 1984 and 1992, only minor degassing was observed at the periphery, at the La Route de la Citerne and Morne Mitan fumaroles, where the La Ty regional fault intersects the lava dome base. A fumarolic reactivation in the summit zone was observed in 1992 at the Cratère Sud. It gradually spread to the North/North-East, and reached the Cratère Napoléon in 1996-97 and, in 1997, the Gouffre Tarissan, which had been very active during the last crisis. A quasi-permanent pond of very acidic water has been noticed since 1997 at the Cratère Sud Sud. At the periphery, most gas emissions continued to wane. From 1998-99, plumes with a significant amount of $\mathrm{HCl}$ have been emitted from the summit and are visible from a few kilometers away $(\mathrm{pH}$ measurements from the Rapport de l'Observatoire Volcanologique et Sismologique de Guadeloupe (1976-2006) and OP-FTIR remote measurements by Bernard et al. (2006).

\subsection{Seismicity}

Since the eruptive crisis that was associated with very high seismicity between 1975 and 1977 (16 000 recorded earthquakes, including 150 felt (Feuillard et al., 1983)), the seismic activity decreased considerably to reach in 1990 its lowest level since 1970 with 32 earthquakes per year (Fig. 2A). Similar to the evolution of the water halogen content (Fig. 2B), this slow decrease was punctuated by peaks of activity. In 1992, a change of regime was observed, with a sharp increase in the number of recorded earthquakes. This coincided with the fumarolic reactivation of the Cratère Sud. Since 1992, most of the recorded earthquakes are shallow high-frequency events with a low magnitude (b 1) and are located between the surface and a depth of $5 \mathrm{~km}$ below the summit (Rapport de l'Observatoire Volcanologique et Sismologique de Guadeloupe, 1976-2006; Komorowski et al., 2005).

\subsection{A common behavior of degassing and seismicity}

We conclude that geophysical and geochemical proxies of La Soufrière's volcanic activity (i.e. chlorine content of Carbet Échelle thermal spring, fumarolic and seismic activities) all evolved similarly in the decade after the 1975-77 crisis, as schematically summarized in Fig. 4. They followed a secular trend slowly decreasing from 1976. A very low level was reached in 1984 for the fumarolic activity, in 1990 for the halogen content of Carbet Échelle and in 1992 for seismic activity. When quantitative data are available (i.e. for all records except fumarolic activity), an episodic pattern is highlighted, super-imposed on this decreasing trend. This shared behavior until 1992 suggests a common physical source. As proposed by Villemant et al. (2005) and Boichu et al. (2008), the episodicity in the halogen content of Carbet Échelle water may suggest the presence of a shallow degassing magma. Boichu et al. (2008) developed a physical model describing the processes controlling the thermodynamic evolution of an andesitic magma intrusion and the episodic nature of its degassing. To explore the hypothesis that the crisis and subsequent activity may have been triggered by a magma intrusion below La Soufrière, we process the halogen content records of the diverse thermal springs to compare with the outputs of the degassing model proposed by Boichu et al. (2008). We note however, after 1992, a divergent evolution: fumarolic and seismic activities increased whereas the halogen content of Carbet Échelle remained very low.

\section{From episodicity in spring water chlorine content to characteristics of La Soufrière's}

\section{shallow magmatic system}

\subsection{Data processing of water chlorine content of La Soufrière thermal springs}

According to the study of Villemant et al. (2005), the fluctuations in the $\mathrm{Cl}$ content of water discharged from the thermal springs contaminated by magmatic fluids on La Soufrière may result from the episodic injection of $\mathrm{Cl}$ pulses into the hydrothermal system. Two time-dependent variables characterize such episodic degassing: the time interval $\Delta$ t between two consecutive $\mathrm{Cl}$ pulses and the number of pulses $\mathrm{N}$ since the first water sampling. Using the time-series of $\mathrm{Cl}$ pulses from Villemant et al. (2005), we deduce the time evolution of $\Delta \mathrm{t}$ and $\mathrm{N}$. This observed evolution is then compared to that produced by the model of Boichu et al. (2008).

\subsubsection{Time-series of $\mathrm{Cl}$ pulses injected into $\mathrm{La}$ Soufrière hydrothermal} system

According to Villemant et al. (2005), the time-series of the $\mathrm{Cl}$ content recorded in Carbet Échelle, Galion, Bains Jaunes and Chutes du Carbet spring water after 1979 (Fig. 3) can be reproduced assuming the injection of a series of discrete $\mathrm{Cl}$ pulses into the hydrothermal system, and using a model of advection-dispersion to describe the transport of this episodic supply by water flow within a porous medium. The further the spring is from the point of injection, the more delayed and spread over time is the associated $\mathrm{Cl}$ anomaly in the spring water. In the case of Carbet Échelle, which is the closest spring from the point of gas injection, the duration of transfer of $\mathrm{Cl}$ pulses appears to be considerably shorter than at other springs. Moreover, distinct pulses are recorded in the $\mathrm{Cl}$ content of Carbet Échelle water, which suggests that the interval of time between consecutive injections is longer than the characteristic time of transport and dispersion for this spring. As a consequence, the inversion of the $\mathrm{Cl}$ record of Carbet Échelle supplies the most precise constraints on the date of $\mathrm{Cl}$ injections into the hydrothermal system. Unfortunately, the sampling of spring water at Carbet Échelle started in January 1979 only, which means that any pulse injected prior to September 1978 cannot be detected at that spring (given the duration of transport of $\sim 3$ months deduced from the inversion). Nevertheless, a more distant spring (Bains Jaunes), with a smoother, more delayed $\mathrm{Cl}$ signal (Fig. 3), suggests that a few injections have occurred prior to September 1978. However, these early injections are poorly constrained, and are consequently not considered in this study.

In their model, Villemant et al. (2005) assume constant normalized flow rates for each spring, while the magnitude and frequency of gas pulses are variable. The impact of rainfall on $\mathrm{Cl}$ variations is neglected, as no correlation is found between rainfall measured at the summit of La Soufrière and the $\mathrm{Cl}$ content of Carbet Échelle spring indicating the absence of a pronounced $\mathrm{Cl}$ dilution effect after rainfalls (Fig. S-1), and the thermal characteristics of this spring are also in disagreement with the occurrence of rainfall-induced $\mathrm{Cl}$ remobilisation (with the largest $\mathrm{Cl}$ pulses clearly related to positive thermal anomalies (Villemant et al., 2005)). Fig. 5A illustrates the time-series of retrieved pulses providing the best fit to the $\mathrm{Cl}$ variations measured at Carbet Échelle. Readers are referred to the paper of Villemant et al. (2005) for details concerning this model inversion.

\subsubsection{Evolution of the time interval between consecutive $\mathrm{Cl}$ pulses at $\mathrm{La}$} Soufrière

Given the series of $\mathrm{Cl}$ pulses injected into La Soufrière hydrother-mal system (Fig. 5A), the time interval between two consecutive pulses, represented in Fig. 5B, is deduced according to the relation:

$$
\Delta \mathrm{t}_{\mathrm{i}}=\mathrm{t}_{\mathrm{i}}-\mathrm{t}_{\mathrm{i}-1}
$$

where $t_{i}$ represents the date of the pulse i. The number of pulses $\mathrm{N}$ since 5 January 1979, corresponding to the first water sampling, is also evaluated (Fig. 5C). An initial regime in the time-series of $\mathrm{Cl}$ pulses is characterized by 
a small time interval $\Delta \mathrm{t}$ ranging from 70 to 140 days between consecutive $\mathrm{Cl}$ pulses. A transition is then observed, with a progressively longer time interval (or a slower increase in the cumulative number of pulses), with $\Delta \mathrm{t}$ increasing up to $\sim 400$ days in 1990-91. No Cl pulse is detected anymore after 1991, while the mean $\mathrm{Cl}$ content of Carbet Échelle water reached a remarkably low level.

This distribution of $\mathrm{Cl}$ pulse injections into the hydrothermal system of $\mathrm{La}$ Soufrière follows an evolution analogous to that predicted by the model for episodic degassing of an andesitic magma intrusion of Boichu et al. (2008). Assuming a shallow magma intrusion, this model highlights a first regime of magma degassing characterized by a high gas pulse frequency, followed by a transition toward a second mode with a lower pulse frequency. The change of regime in magma degassing is proposed to result from the rapid increase of magma viscosity after magma crystallinity exceeded the crystal percolation threshold, therefore slowing the processes of magma cooling, volatile exsolution and degassing. This analogy between observations and model predictions suggests that a shallow magma intrusion at La Soufrière could have led to the 1975-77 eruptive crisis and subsequent degassing activity. In the following section, we perform an inversion of the time-series of $\mathrm{Cl}$ pulses using this model of episodic degassing.

\subsection{Application of a model for episodic degassing of an andesitic magma intrusion to the case of La Soufrière}

The physical model of Boichu et al. (2008) describes the thermodynamic evolution of a water-saturated andesitic magma intruded at shallow depth in the crust (Fig. 6). Driven by the thermal contrast between magma and surrounding rocks, the intrusion cools by convection, crystallizes and exsolves volatiles. When the magma overpressure induced by volatile exsolution reaches a critical threshold, host rocks fracture and gas escapes. The intrusion then returns to lithostatic pressure and a new cooling-crystallization-degassing cycle starts. A series of such cycles leads to the episodic degassing of the intruded magma. For a detailed description of this model, the reader is referred to the paper of Boichu et al. (2008).

Among model input parameters, five play a predominant role on magma degassing:

(1) the tensile strength $\sigma$ of the surrounding rocks defining the critical overpressure capable of fracturing host rocks,

(2) the radius $\mathrm{R}$ of the magma intrusion, assumed of spherical shape,

(3) the initial crystal content $\Phi_{\mathrm{i}}$ of the magma,

(4) the initial temperature contrast $\Delta \mathrm{T}$ between magma and surrounding rocks,

(5) the depth $\mathrm{z}$ of magma intrusion.

In the following, our aim is to determine the values of the model inputs that minimize the difference between modeled and measured evolutions of the variables $\Delta \mathrm{t}$ and $\mathrm{N}$ describing the degassing activity at La Soufrière. The range of realistic values for these parameters can be constrained a priori in the light of our current knowledge about andesitic magmas and La Soufrière's volcanic system.

First, the phenocryst content of andesitic magmas is a good approximation of the initial crystal content $\Phi_{\mathrm{i}}$ of a magma intruded below La Soufrière, as microlites and nanolites are likely formed in the last kilometers of magma ascent to the surface. Phenocryst contents observed in andesitic magmas of the Lesser Antilles cover a range in 30-50 vol.\% (Villemant and Boudon, 1999; Sparks et al., 2000). Nevertheless, the content in phenocrysts may represent an upper bound for the estimation of $\Phi_{i}$ given the potential overgrowth of phenocrysts accompanying rapid magma rise to the surface (Blundy and Cashman, 2005).

The depth $\mathrm{z}$ of a potential magma batch intruded below La Soufrière can be considered in the $2-5 \mathrm{~km}$ range according to diverse observations. Earthquake foci for the period 1975-77 are located $0.5-6 \mathrm{~km}$ below sea level with most of them ranging in $1-3 \mathrm{~km}$ b.s.l. (Feuillard et al., 1983). The initiation of the rapid vertical migration of major earthquake swarms in 1976 (Hirn and Michel, 1979), as well as the source for geomagnetic field intensity anomalies observed in 1976-77 (Pozzi et al., 1979; Feuillard et al., 1983), were shown to be at a depth of $\sim 6 \mathrm{~km}$. The chamber feeding the last magmatic eruption at La Soufrière was also estimated to be located at nearly the same depth, according to petrological studies (Semet et al., 1981).

The temperature contrast $\Delta \mathrm{T}$ between magma and surrounding rocks depends on magma depth, geothermal gradient and local thermal anomalies which are not well constrained concerning La Soufrière. Thus, $\Delta \mathrm{T}$ is assumed to vary in a wide range of $200-600 \mathrm{~K}$.

Finally, plausible values for the tensile strength of the host rocks $\sigma$ are poorly constrained and may cover a broad range (0.01-10 MPa) depending on the extent of pre-existing fractures (Touloukian et al., 1981; Tait et al., 1989; Rowe et al., 1992).

As shown by Boichu et al. (2008), $\Delta \mathrm{t}$ and $\mathrm{N}$ are mainly sensitive to the tensile strength $\sigma$ of the host rocks and the volume of the intrusion. $\sigma$ defines the critical overpressure needed for wall rock failure, which strongly constrains the value of the interval of time between successive gas pulses. On the other hand, the intrusion radius R strongly controls the strength of magma convection and the associated rates of magma cooling and crystallization. Therefore, $\mathrm{R}$ has a large influence on the time of transition between the first regime of degassing punctuated by frequent gas pulses, and the second mode with less frequent expulsions of gas. In contrast, within their range of realistic values, the parameters $\Phi_{i}, \Delta \mathrm{T}$ and $\mathrm{z}$ have a significantly weaker impact on the evolution of $\Delta \mathrm{t}$ and $\mathrm{N}$. Consequently, our approach consists in fixing these secondary input parameters to a mid-range value $\left(\Phi_{\mathrm{i}}=40 \mathrm{vol} . \%, \Delta \mathrm{T}=400 \mathrm{~K}\right.$, $\mathrm{z}=3 \mathrm{~km}$ ) to find the values of $\sigma$ and $\mathrm{R}$ yielding the best fit of $\mathrm{t}$ to the data for La Soufrière. The predicted distribution of $\Delta t$ and $\mathrm{N}$ as a function of time, for the best solution ( $R=320 \mathrm{~m}, \sigma=0.3 \mathrm{MPa}$ ), is shown in Fig. 7. We find that values of $\sigma$ in the range $0.1-0.6 \mathrm{MPa}$ bracket the observed values of $\Delta \mathrm{t}$. We evaluate in the next section the uncertainty on this solution by exploring the model sensitivity to secondary input parameters.

\subsection{Model sensitivity and retrieved characteristics of $\mathrm{La}$ Soufrière's subsurface magmatic system}

Fig. 8 illustrates the model sensitivity to the main input parameters $(\sigma, R$, $\Phi_{\mathrm{i}}, \Delta \mathrm{T}$, and $\mathrm{z}$ ). The role of each of these parameters can be described by their respective influence on the time of transition between degassing regimes, and/or on the order of magnitude of the time interval $\Delta t$ between consecutive pulses.

Host rock tensile strength $\sigma$ and the depth of magma storage $z$ only influence the amplitude of $\Delta t$, whereas other parameters simultaneously impact both $\Delta t$ and the time of transition to the second regime of degassing (Fig. 8A and E). Magma depth governs the solubility of volatiles in the melt and the quantity of dissolved gas available for exsolution for a given increase of the crystal fraction. $\mathrm{z}$ is consequently involved in the process of magma pressurization. Nevertheless, in comparison with $\sigma$ which constrains the order of magnitude of the critical pressure for host rock failure, $\mathrm{z}$ has a minor importance on the duration of a cycle of magma pressurization. In contrast, R, $\Delta \mathrm{T}$ and $\Phi_{\mathrm{i}}$ all control, directly or indirectly, the vigor of convection within the reservoir and therefore the process of magma cooling and the time of transition between degassing regimes (Fig. 8B, C and D). As discussed in the previous section, the most important control on convection is exerted by $\mathrm{R}$, but a significant role is also played by magma viscosity, which depends on many parameters including magma temperature, crystal and bubble content, melt composition and dissolved water content. In the present case of an andesitic magma, the high crystallinity implies that viscosity is primarily controlled by the crystal content $\Phi$ (Boichu et al., 2008). Consequently, the time of regime transition depends predominantly on $\mathrm{R}$, more modestly on $\Delta \mathrm{T}$ and $\Phi_{\mathrm{i}}$, and is least dependent on $\sigma$ and $\mathrm{z}$.

In order to determine the uncertainty on the estimation of $\mathrm{R}$, we explore the variations in the time of regime transition when $\Delta \mathrm{T}$ and $\Phi_{\mathrm{i}}$ vary in their range of realistic values. When $\mathrm{R}=320 \mathrm{~m}$ (value of $\mathrm{R}$ corresponding to the best model fit to data in Fig. 7), the longest delay before regime transition ( 20 years) in the modeled evolution of $\Delta \mathrm{t}$ is obtained for the lowest value of $\Delta \mathrm{T}$ (i.e. $200 \mathrm{~K}$ ) as shown in Fig. $8 \mathrm{D}$. If $\Delta \mathrm{T}$ is fixed to this lowest value, a good model fit to data is again obtained - with a time of regime transition in agreement with the observations in the range $\sim 5-10$ years following a magma intrusion assumed on $1 / 7 / 76$ - for a radius of $\sim 150 \mathrm{~m}$ (Fig. 9A). On the other 
hand, the upper bound for the range of plausible $\mathrm{R}$ values is estimated by considering the earliest time for regime transition ( $\sim 4$ years), which is obtained for the highest value of $\Phi_{\mathrm{i}}$ (i.e. 45 vol.\%) as shown in Fig. 8C. If $\Phi_{\mathrm{i}}$ is fixed to this highest value, a good model fit to data is also reached for a radius of $\sim 500 \mathrm{~m}$ (Fig. 9B). This particular set of parameters requires a slight decrease of $\sigma$ by $0.1 \mathrm{MPa}$ to reproduce the observed interval of time between pulses.

Moreover, another source of uncertainty stems from the unknown date of emplacement of magma at shallow depth. The choice of this date (1/7/76) is supported by the observation of a rapid vertical migration (in a few hours) of successive strong shocks in July and August 1976 (Hirn and Michel, 1979), which can be associated to magma intrusion. However, the increase of the seismic activity observed since July 1975 (Dorel and Feuillard, 1980) presumes that magma ascent may have occurred during the year preceding the first phreatic explosion in July 1976. Given the model sensitivity to input parameters, the uncertainty in the date of magma intrusion leads to an uncertainty of about 1 year in the time of regime transition at La Soufrière, with a negligible impact on the estimated range of $R$ values (150-500 m).

Finally, $\Phi_{\mathrm{i}}$ has a negligible impact on the time interval between gas pulses, at least in the first regime of degassing (Fig. $8 \mathrm{C}$ ). $\Delta \mathrm{T}$ and $\mathrm{R}$ can cause variations of the amplitude of $\Delta t$ given their influence on the rates of volatile exsolution and associated magma pressurization, but to a negligible extent in comparison with $\sigma$. A trade-off is also observed between the respective influence of $\Delta \mathrm{T}$ and $\mathrm{R}$ on the degassing activity (Fig. $8 \mathrm{~B}$ and $\mathrm{D}$ ). Consequently, the range of estimated $\sigma$ values of $0.1-0.6 \mathrm{MPa}$, which brackets the observed values of $t$ at La Soufrière (Fig. 7), remains valid given the limited impact of the other input parameters on $\Delta \mathrm{t}$.

\section{Discussion}

\subsection{Implications for La Soufrière's subsurface magmatic system}

The time-series of magmatic gas pulses deduced from the $\mathrm{Cl}$ content of $\mathrm{La}$ Soufrière's thermal springs, together with the physical model of Boichu et al. (2008), allow us to evaluate the radius of a potential magma intrusion preceding the phreatic crisis of July 1976. A radius ranging in $150-500 \mathrm{~m}$ is estimated, equivalent to a magma volume of $0.01-0.52 \mathrm{~km}^{3}$. This is comparable to the magnitude of the last magmatic eruption of La Soufrière in $1530 \mathrm{AD}$ of $\sim 0.1 \mathrm{~km}^{3}$ (Komorowski et al., 2005) and to the total erupted volume $\leq 0.5 \mathrm{~km}^{3}$ estimated for the four magmatic eruptions recorded in the last 3000 years (Boudon et al., 2008). The estimated 0.1-0.6 MPa tensile strength of host rocks at La Soufrière is at the low end of the range of values (0.01-50 MPa) found in the literature. As shown by Rothert and Shapiro (2007), it may be compatible with the strength of rocks containing preexisting cracks.

These retrieved characteristics of La Soufrière's subsurface mag-matic system are reasonable and strengthen the hypothesis that a magma may have intruded at shallow depth around 1976, triggering the 1975-77 crisis and producing the $\mathrm{Cl}$ fluctuations observed in thermal springs water over the following decades. This interpretation is also compatible with the significant 1975-77 seismic crisis culminating on the 16 August 1976 with an earthquake of magnitude $M=4.5$, and including two earthquakes of magnitude $M=4$ and about thirty of magnitude $\mathrm{M}>3$ (Dorel and Feuillard, 1980), the location of hypocenters observed down to $6 \mathrm{~km}$ below sea level (Dorel and Feuillard, 1980; Feuillard et al., 1983), the rapid vertical migration (a few hours) of larger events from a depth of $\sim 6 \mathrm{~km}$ toward the surface in July and August 1976 (Hirn and Michel, 1979), and the magnetic field intensity anomalies with a source of perturbation estimated at $\sim 6 \mathrm{~km}$ depth (Pozzi et al., 1979; Feuillard et al., 1983). Finally, this magma intrusion could account for the significant amounts of magmatic gases $\left(\mathrm{CO}_{2}, \mathrm{SO}_{2}\right.$ and $\left.\mathrm{H}_{2} \mathrm{~S}\right)$ and acid condensates (including fluorine and chlorine) recorded during the crisis (Le Guern et al., 1980; Komorowski et al., 2005), as well as the temperature increase of gas emissions (up to $200{ }^{\circ} \mathrm{C}$ ) and water of Carbet Échelle, the closest spring from the lava dome summit $\left(70{ }^{\circ} \mathrm{C}\right.$ recorded in 1979 compared with approximately ambient temperature today) (Villemant et al., 2005). to 1992

\subsubsection{Decay in degassing and seismic activities after the $1975-77$ crisis}

The results from the analysis of La Soufrière's degassing through thermal springs since 1979 presented in this study shed new light on the last crisis and the subsequent volcanic activity. We propose the following interpretation of the degassing and seismic activities observed since 1975 (Fig. 10). A magma intrusion stalled at shallow depth in 1975-76, accompanied by an increase of seismicity. Liberation of gases from ascending magma and aquifer vaporization led to the many phreatic explosions observed since July 1976 (Fig. 10A). After emplacement, magma cooled, crystallized and its episodic degassing fed the entire volcanic system, supporting fumaroles and elevating the halogen content in thermal springs. Volatile flux induced by second boiling is weaker than during magma ascent. Gases are consequently more dispersed through the edifice and the temperature of the hydrothermal system may decrease. Both these processes enhance magmatic gas scrubbing by the hydrother-mal system (Symonds et al., 2001). As a result, fumarole flux decreased, and finally faded away in 1983-84. However, the halogen content of Carbet Échelle water, characterized by regular high-frequency fluctuations, attests to the continuation of episodic magma degassing at depth (Fig. 10B). The similar episodic behavior observed in seismicity, with peaks of activity, can arise from various intermittent mechanisms following magma intrusion. Seismogenic processes could include episodic pressuring accompanying the crystallization of the intruded magma; repeated fracturing of surrounding rocks and expected stress readjustments around magma; potential hydraulic fracturing by gas episodically liberated from the intrusion; or resonance of fluid filled fissures of the hydrothermal system (Neuberg, 2000). In relation to the thermody-namic evolution of the shallow magma, a progressive change in the regime of degassing occurs with less frequent gas expulsions released from the intrusion, which plays a role in the decrease of the mean chlorine content of Carbet Échelle water and of seismicity (Figs. 2 and 4). Episodically released gases continued contaminating Carbet Échelle thermal spring until 1992.

\subsubsection{Sealing of the aquifer feeding Carbet Échelle spring}

The episodic degassing observed in the thermal spring of Carbet Échelle vanished after 1992 (Fig. 5) whereas the model, fitted to La Soufrière's data, predicts its continuation with $\sim 1 \mathrm{Cl}$ pulse per year (Fig. 7). To explain this discrepancy, we suggest the sealing of the aquifer feeding Carbet Échelle. Sealing mechanisms are commonly observed in geothermal or volcanic areas (Zlotnicki et al., 1992; Fischer et al., 1994; Harris and Maciejewski, 2000; Dobson et al., 2003; Christenson et al., 2010). Different observations support their significant development at La Soufrière. Products of flank destabilization and current active areas at the summit show a large hydrothermal alteration through clay deposits, promoting the clogging of edifice pores and fractures. The emission of hot and acid gases expelled from the intrusion between 1975-76 and 1992 may have promoted alteration and precipitation of minerals favoring the development of sealing processes in shallow parts of the hydrother-mal system. This process is also supported by geo-electrical tomogra-phy, electromagnetic and self potential studies which identify faults and significant clay deposits particularly in the NE lava dome part isolating today Carbet Échelle (Zlotnicki et al., 1992; Nicollin et al., 2006; Zlotnicki et al., 2006). Finally, the current ambient temperature of this spring, compared with the $70{ }^{\circ} \mathrm{C}$ recorded in 1979 , attests to its isolation from hydrothermal fluids (Villemant et al., 2005). Each episodic pulse of gas released from the magma body may nevertheless perturb this closure of the edifice. Sealing mechanisms are consequently accelerated with the progressive decrease in gas pulse frequency (Fig. 10C).

\subsubsection{Reactivation of the seismic and fumarolic activities in 1992}

In 1992, a reappearance of fumaroles at the lava dome summit (Cratère Sud) was observed, simultaneously with a reactivation of seismicity which had reached a very low level with only 32 recorded shocks in the two preceding years (Fig. 2). This unrest was accompanied by predominantly shallow high-frequency earthquakes of low magni-tude and weak emissions of sulfurous gases, with fumaroles mostly composed of $\mathrm{H}_{2} \mathrm{O}$ and $\mathrm{CO}_{2}$ and, to 
a lesser extent, of $\mathrm{HCl}$ and $\mathrm{H}_{2} \mathrm{~S}$ (Rapport de l'Observatoire Volcanologique et Sismologique de Guadeloupe, 1976-2006; Komorowski et al., 2005). No large scale ground deformation was measured.

Despite an absence of explosive behavior, of significant amounts of $\mathrm{SO}_{2}$ emissions and of a continuous increase of seismicity in the preceding years, the activity in 1992 presents some similarities with the 1975-77 crisis, with surface manifestations which are however of significantly lesser extent. Analogous scenarios to those proposed for the origin of the 1976 crisis could thus be invoked, involving either a magmatic (Feuillard et al., 1983; Villemant et al., 2005) or a hydrothermal control (Zlotnicki et al., 1992). However, we note a striking coincidence in 1992, with the isolation of Carbet Échelle spring simultaneous with the renewal of the fumarolic activity at the summit. This favors an interpretation involving a redistribution of fluid pathways within the volcanic edifice and hydrothermal system, according to a mechanism similar to that proposed by Zlotnicki et al. (1992) to interpret the recurrence of phreatic crisis at La Soufrière.

We suggest that sealing of superficial parts of the hydrothermal system may have been developing after the end of the phreatic crisis and became significant in 1992 when the aquifer feeding Carbet Échelle was isolated (Fig. 10C). Because of these clogging processes, magmatic fluids which were episodically expelled from the 1976 intrusion were less efficiently transferred via the hydrothermal system. This progressive confinement led to pressurization of the edifice and numerous rock micro-failures, which may yield the seismicity observed since 1992 with mostly shallow high-frequency earthquakes of low magnitude (Rapport de l'Observatoire Volcanologique et Sismologique de Guadeloupe, 1976-2006; Komorowski et al., 2005). Eventually, gases were prefer-entially driven to the summit by large fractures crossing the lava dome, rejuvenating fumaroles at Cratère Sud (Fig. 10D). The vertical conductive channel coming out in the summit zone (Cratère Sud and Gouffre Tarissan), which has been highlighted by geo-electrical tomography performed after 2001, may represent the preferential path for hydrothermal and magmatic fluids (Nicollin et al., 2006). Consequently, the increase of activity in 1992 may result from the on-going degassing of the magma intruded in 1975-76. In this case, according to our physical model (Boichu et al., 2008), gasses expelled at La Soufrière over the 30 years following the 1976 magma intrusion may represent only 25 to $40 \%$ of the initial mass of dissolved gas.

\section{Conclusion}

Variations of $\mathrm{Cl}$ content in thermal springs of La Soufrière since the 1975-77 crisis may be explained by a series of magmatic gas pulses which, once injected in the hydrothermal system, are transported and dispersed by water flow (Villemant et al., 2005). A characteristic of this pulsatory timeseries of $\mathrm{Cl}$ content is the transition from a first regime with frequent gas expulsions ( $\sim 1$ pulse per 70-140 days) to a progressively lower pulse frequency. This pattern in degassing may result from a shallow magma intrusion episodically expelling gas. As shown in the physical model of Boichu et al. (2008), cycles of magma cooling, crystallization and volatile exsolution lead to magma overpressure until surrounding rock failure which allows exsolved gas to escape. Magma cooling by convection, and associated pressure build-up and gas expulsion, significantly slow after a rapid increase of viscosity when magma crystallinity exceeds the threshold of crystal percolation. The time of the resulting transition between degassing regimes is mainly controlled by magma volume, whereas the amplitude of the time interval between gas pulses is dominated by the tensile strength of the host rock. La Soufrière's degassing behavior until 1992 is reproduced by this physical model, considering a magma intrusion volume in the range $0.01-0.52$ $\mathrm{km}^{3}$ and a tensile strength of the surrounding rock in the range 0.1-0.6 MPa.

This result strengthens the hypothesis of a shallow magma intrusion which may have triggered the 1975-77 crisis and explains the episodic pattern of degassing and seismicity superimposed on a decennial decreasing trend. A redistribution of fluid pathways associated with sealing processes in the uppermost parts of the volcanic edifice, favoring the transfer of gases to the summit fumarolic vents, may explain the absence of $\mathrm{Cl}$ pulses in thermal springs after 1992 and the simultaneous reactivation of seismicity and fumarolic emissions. In addition to gas discharge and associated seismicity, a magma intrusion involves mechanical and thermal perturbations which may weaken a volcanic edifice already considerably weakened by a vigorous hydrothermal system. La Soufrière de Guadeloupe has experienced frequent flank collapses, with $\sim 10$ recorded over the past 15,000 years (Komorowski et al., 2005; Boudon et al., 2008). The scenario of a magma intruded at shallow depth around 1976 thus has implications in terms of hazard assessment for future crises of this volcano.

In the future, this interpretation of La Soufrière's degassing may stimulate investigations of similar observations of episodic degassing behavior collected at other volcanoes like at the Phlegrean Fields (Chiodini et al., 2003, Todesco et al. 2003, D'Auria et al., 2011).

Supplementary materials related to this article can be found online at doi: 10.1016/j.jvolgeores.2011.04.007.

\section{Acknowledgments}

This study would not have been possible without the tremendous efforts of Gilbert Hammouya who sampled the waters of all the thermal springs of $\mathrm{La}$ Soufrière with a remarkable frequency during decades, despite the difficult access to many of them, and the commitment of the staff of the "Observatoire Volcanologique et Sismologique de la Guadeloupe" to monitoring tasks. We also thank the staff of the "Observatoire Volcanologique et Sismologique de la Guadeloupe" for data compilation. We are also particularly grateful to Clive Oppenheimer and David Pyle for their constructive comments on an earlier version of this paper which greatly helped to improve the manuscript. This article also benefited from helpful remarks of Giovanni Chiodini, as editor and reviewer of this paper. This study has been partially carried out during the ANR Risk-Volc-An and is the IPGP contribution number 3162. $\mathrm{MB}$ also acknowledges support from the European Commission for her IntraEuropean Marie-Curie Fellowship (Project VolcanGas 14018) which allowed her to take the time to revise this manuscript.

\section{References}

Barrabé, L., Jolivet, J., 1958. Les récentes manifestations d'activité de la Guadeloupe (Petites Antilles). Bull. Volcanol. 19, 143-158.

Bernard, M., Molinié, J., Petit, R., Beauducel, F., Hammouya, G., Marion, G., 2006. Remote and in situ plume measurements of acid gas release from La Soufrière volcano, Guadeloupe. J. Volcanol. Geotherm. Res. 150, 395-409.

Bigot, S., Hammouya, G., 1987. Surveillance hydrogéochimique de la Soufrière de Guadeloupe, 1979-1985: diminution d'activité ou confinement? C. R. Acad. Sci. Paris 304 (13), 757760.

Blundy, J., Cashman, K., 2005. Rapid decompression-driven crystallisation recorded by melt inclusions from Mount St-Helens volcano. Geology 33 (10), 793-796.

Boichu, M., Villemant, B., Boudon, G., 2008. A model for episodic degassing of an andesitic magma intrusion. J. Geophys. Res. 113, B07202.

Boudon, G., Semet, M., Komorowski, J.-C., Villemant, B., Michel, A., 2008. A new scenario for the last magmatic eruption of La Soufrière of Guadeloupe (Lesser Antilles) in 1530 A.D. Evidence from stratigraphy radiocarbon dating and magmatic evolution of erupted products. J. Volcanol. Geotherm. Res. 178, 474-490.

Boudon, G., Semet, M., Vincent, P., 1989. The evolution of La Grande Découverte (La Soufrière) volcano, Guadeloupe (F.W.I.). Proceedings in Volcanology-Volcano Hazards: Assessment and Monitoring. Montagne Pelée 1902-2002: Saint-Pierre, Martinique, IPGP, IAVCEI. Springer-Verlag, pp. 86-109.

Brombach, T., Marini, L., Hunziker, J., 2000. Geochemistry of the thermal springs and fumaroles of Basse-Terre Island, Guadeloupe, Lesser Antilles. Bull. Volcanol. 61, 477-490.

Chiodini, G., Todesco, M., Caliro, S., Del Gaudio, C., Macedonio, G., Russo, M., 2003. Magma degassing as a trigger of bradyseismic events: the case of Phlegrean Fields (Italy). Geophys. Res. Lett. 30 (8), 1434.

Christenson, B., Reyes, A., Young, R., Moebis, A., Sherburn, S., Cole-Baker, J., Britten, K. 2010. Cyclic processes and factors leading to phreatic eruption events: insights from the 25 September 2007 eruption through Ruapehu Crater Lake, New Zealand. J. Volcanol Geotherm. Res. 191, 15-32.

D'Auria, L., Giudicepietro, F., Aquino, I., Borriello, G., Del Gaudio, C., Lo Bascio, D., Martini, M., Ricciardi, G.P., Ricciolino, P., Ricco, C., 2011. Repeated fluid-transfer episodes as a mechanism for the recent dynamics of Campi Flegrei caldera (1989-2010). J. Geophys. Res. 116, B04313.

Dobson, P., Kneafsey, T., Hulen, J., Simmons, A., 2003. Porosity, permeability, and fluid flow in the Yellowstone geothermal system, Wyoming. J. Volcanol. Geotherm. Res. 123, 313-324.

Dorel, J., Feuillard, M., 1980. Note sur la crise sismo-volcanique à la Soufrière de la Guadeloupe 1975-1977. Bull. Volcanol. 43-2, 419-430.

Edmonds, M., Oppenheimer, C., Pyle, D., Herd, R., Thompson, G., 2003. $\mathrm{SO}_{2}$ emissions from Soufrière Hills Volcano and their relationship to conduit permeability, hydrothermal interaction and degassing regime. J. Volcanol. Geotherm. Res. 124, 23-43.

Feuillard, M., Allègre, C., Brandeis, G., Gaulon, R., Le Mouel, J., Mercier, J., Pozzi, J., Semet, M., 1983. The 1975-1977 crisis of La Soufrière de Guadeloupe: a still-born magmatic eruption. J. Volcanol. Geotherm. Res. 16, 317-334.

Fischer, T., Arehart, G., Sturchio, N., Williams, S., 1996. The relationship between fumarole gas composition and eruptive activity at Galeras Volcano, Colombia. Geology 24, 531-534.

Fischer, T.P., Morrissey, M.M., Calvache, M.L., Gomez, D., Torres, R., Stix, J., Williams, S.N., 1994. Correlations between SO2 flux and long-period seismicity at Galeras Volcano. Nature 
$368,135-137$.

Giggenbach, W., Sheppard, D., 1989. Variations in the temperature and chemistry of White Island fumarole discharges 1972-85. N.Z. Geol. Surv. Bull. 103, 119-126.

Harris, A., Maciejewski, A., 2000. Thermal surveys of the Vulcano Fossa fumarole field 19941999: evidence for fumarole migration and sealing. J. Volcanol. Geotherm. Res. 102, 119147.

Hirn, A., Michel, B., 1979. Evidence of migration of main shocks during major seismo-volcanic crises of La Soufrière (Guadeloupe, Lesser Antilles) in 1976. J. Volcanol. Geotherm. Res. 6, 295-304.

Ingebritsen, S., Galloway, D., Colvard, E., Sorey, M., Mariner, R., 2001. Time-variation of hydrothermal discharge at selected sites in the western United States: implications for monitoring. J. Volcanol. Geotherm. Res. 111, 1-23.

Jolivet, J., 1958. La crise volcanique de 1956 à la Soufrière de la Guadeloupe. Annales de Géophysique 14, 305-322. Komorowski, J., Boudon, G., Semet, M., Beauducel, F., AnténorHabazac, C., Bazin, S., Hammouya, G., Cheminée, J., 2005. Guadeloupe. In: Lindsay, J.M., Robertson, R.E.A., Shepherd, J.B., John, L., Ali, S. (Eds.), Volcanic Atlas of the Lesser Antilles. University of the West Indies, pp. 63-100.

Le Guern, F., Bernard, A., Chevrier, R., 1980. Soufrière of Guadeloupe 1976-77 eruption: mass and energy transfer and volcanic health hazards. Bull. Volcanol. 43 (3), 577-593.

López, D., Bundschuh, J., Soto, G., Fernández, J., Alvarado, G., 2006. Chemical evolution of thermal springs at Arenal Volcano, Costa Rica: effect of volcanic activity, precipitation, seismic activity, and earth tides. J. Volcanol. Geotherm. Res. 167, 166-181.

Moran, S.C., Newhall, C., Roman, D.C., 2011. Failed magmatic eruptions: late-stage cessation of magma ascent. Bull. Volcanol. 73, 115-122.

Neuberg, J., 2000. Characteristics and causes of shallow seismicity in andesite volcanoes. Phil. Trans. R. Soc. Lond Ser. A 358, 1533-1546.

Nicollin, F., Gibert, D., Beauducel, F., Boudon, G., Komorowski, J., 2006. Electrical tomography of La Soufrière of Guadeloupe Volcano: field experiments, 1D inversion and qualitative interpretation. Earth Planet. Sci. Lett. 244, 709-724.

Nuccio, P., Paonita, A., 2001. Magmatic degassing of multicomponent vapors and assessment of magma depth: application to Vulcano Island (Italy). Earth Planet. Sci. Lett. 193, 467-481.

Ohba, T., Hirabayashi, J., Nogami, K., 2008. Temporal changes in the chemistry of lake water within Yugama Crater, Kusatsu-Shirane Volcano, Japan: implications for the evolution of the magmatic hydrothermal system. J. Volcanol. Geotherm. Res. 178, 131-144.

Pozzi, J., Le Mouel, J.-L., Rossignol, J., Zlotnicki, J., 1979. Magnetic observations made on La Soufrière Volcano (Guadeloupe) during the 1976-1977 crisis. J. Volcanol. Geotherm. Res. $5,217-237$.

Rapports de l'Observatoire Volcanologique et Sismologique de Guadeloupe, 1976-2006. Bilan mensuel de l'activité volcanique et de la sismicité régionale de l'Observatoire Volcanologique de la Soufrière. Tech. rep., Institut de Physique du Globe de Paris.

Rothert, E., Shapiro, S., 2007. Statistics of fracture strength and fluid-induced microseismicity. J. Geophys. Res. 112, B04309.

Rowe, G., Ohsawa, S., Takano, B., Brantley, S., Fernandez, J., Barquero, J., 1992. Using Crater Lake chemistry to predict volcanic activity at Poas Volcano, Costa Rica. Bull. Volcanol. 54, 494-503.

Semet, M., Vatin-Perignon, N., Vincent, P., Joron, J., 1981. L'éruption du XVIème siècle de la Soufrière de Guadeloupe, mélange de magmas et dynamisme éruptif. Bull. PIRPSEV CNRS $60,1-63$.

Sparks, R., Murphy, M., Lejeune, A., Watts, R., Barclay, J., Young, S., 2000. Control on the emplacement of the andesite lava dome of the Soufrière Hills volcano by degassing-induced crystallisation. Terra Nova 12, 14-20.

Symonds, R.B., Gerlach, T.M., Reed, M.H., 2001. Magmatic gas scrubbing: implications for volcano monitoring. J. Volcanol. Geotherm. Res. 108, 303-341.

Tait, S., Jaupart, C., Vergniolle, S., 1989. Pressure, gas content and eruption periodicity of a shallow, crystallising magma chamber. Earth Planet. Sci. Lett. 92, 107-123.

Todesco, M., Chiodini, G., Macedonio, G., 2003. Monitoring and modelling hydrothermal fluid emission at La Solfatara (Phlegrean Field, Italy). An interdisciplinary approach to the study of diffuse degassing. J. Volcanol. Geotherm. Res. 125, 57-79.

Touloukian, Y., Judd, W.R., Roy, R., 1981. Physical Properties of Rocks and Minerals. Data Series on Material Properties, vol. 1-2. McGraw-Hill.

Vandemeulebrouck, J., Hurst, A., Scott, B., 2008. The effects of hydrothermal eruptions and a tectonic earthquake on a cycling crater lake (Inferno Crater Lake, Waimangu, New Zealand). J. Volcanol. Geotherm. Res. 178, 271-275.

Vandemeulebrouck, J., Stemmelen, D., Hurst, T., Grangeon, J., 2005. Analogue modeling of instabilities in crater lake hydrothermal systems. J. Geophys. Res. 110, B02212.

Villemant, B., Boudon, G., 1999. $\mathrm{H}_{2} \mathrm{O}$ and halogen (F, Cl, Br) behaviour during shallow magma degassing processes. Earth Planet. Sci. Lett. 168, 271-286.

Villemant, B., Hammouya, G., Michel, A., Semet, M.P., Komorowski, J.-C., Boudon, G., Cheminée, J.-L., 2005. The memory of volcanic waters: shallow depth magma degassing revealed by halogen monitoring in thermal springs of La Soufrière volcano (Guadeloupe, Lesser Antilles). Earth Planet. Sci. Lett. 237, 710-728

Zlotnicki, J., Boudon, G., Le Mouel, J.-L., 1992. The volcanic activity of La Soufrière de Guadeloupe (Lesser Antilles): structural and tectonic implications. J. Volcanol. Geotherm. Res. 49, 91-104

Zlotnicki, J., Vargemezis, G., Mille, A., Bruère, F., Hammouya, G., 2006. State of the hydrothermal activity of Soufrière of Guadeloupe volcano inferred by VLF surveys. J. Appl. Geophys. 58, 265-279. 


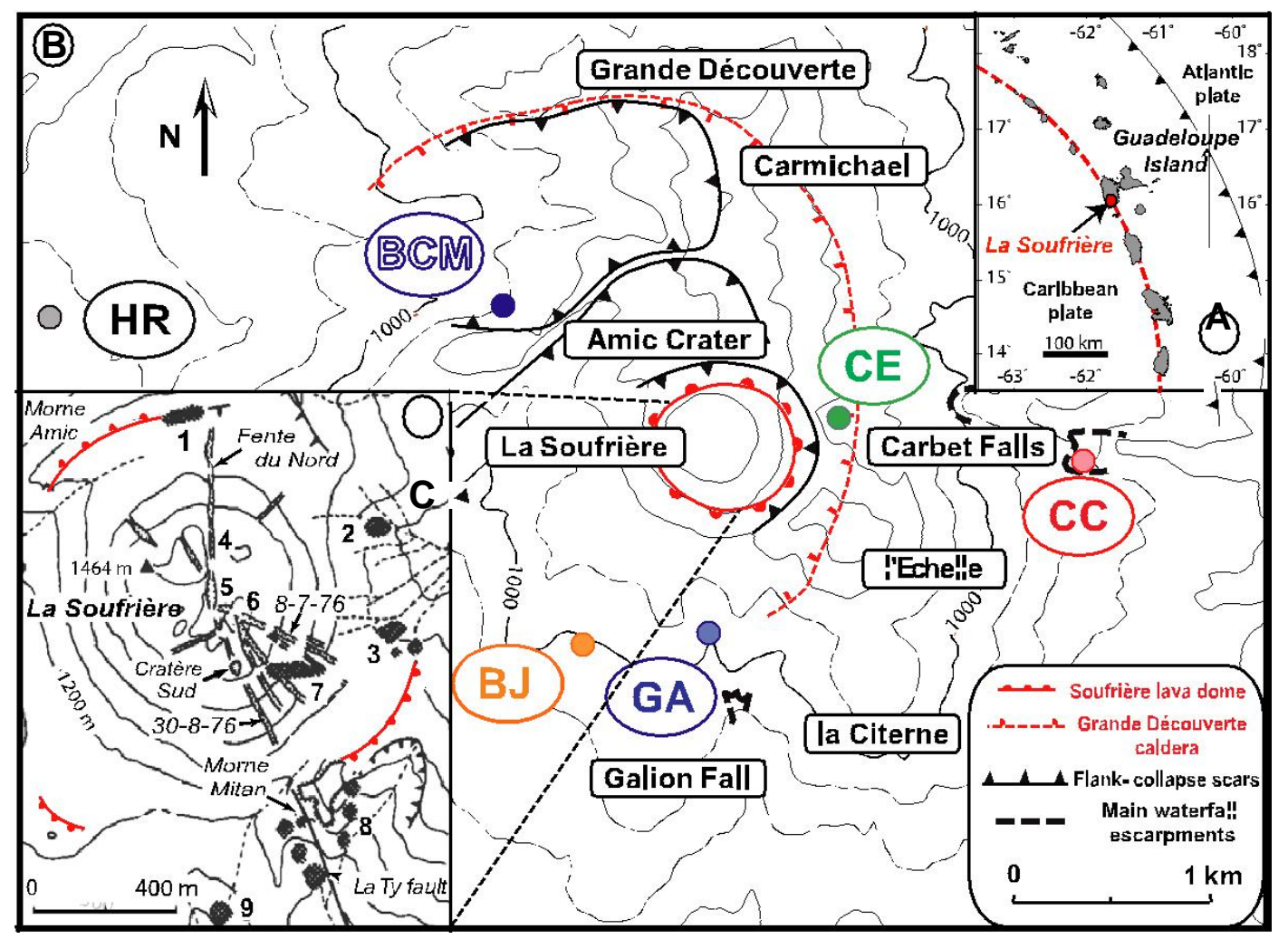

Fig. 1. (A) Map of the Lesser Antilles volcanic island arc. (B) Structural map of La Grande Découverte-La Soufrière volcano including geochemically surveyed thermal springs around La Soufrière lava dome: Carbet Échelle (CE), Bains Jaunes (BJ), Galion (Ga), Chutes du Carbet (CC), Bains Chauds du Matouba (BCM) and Habitation Revel (HR) (modified by Villemant et al. (2005)). (C) Detailed map of La Soufrière lava dome with main fractures and fumarolic areas (intermittently active, see text): 1-Colardeau, 2-Carbetl'Échelle, 3-Chaudières-Souffleur, 4-Gouffre Dupuy, 5-Gouffre Tarissan, 6-Cratère Napoléon, 7-Lacroix, 8-Claire river, 9-Matylis (Galion) (modified from (modified from Zlotnicki et al. (1992)). 
A

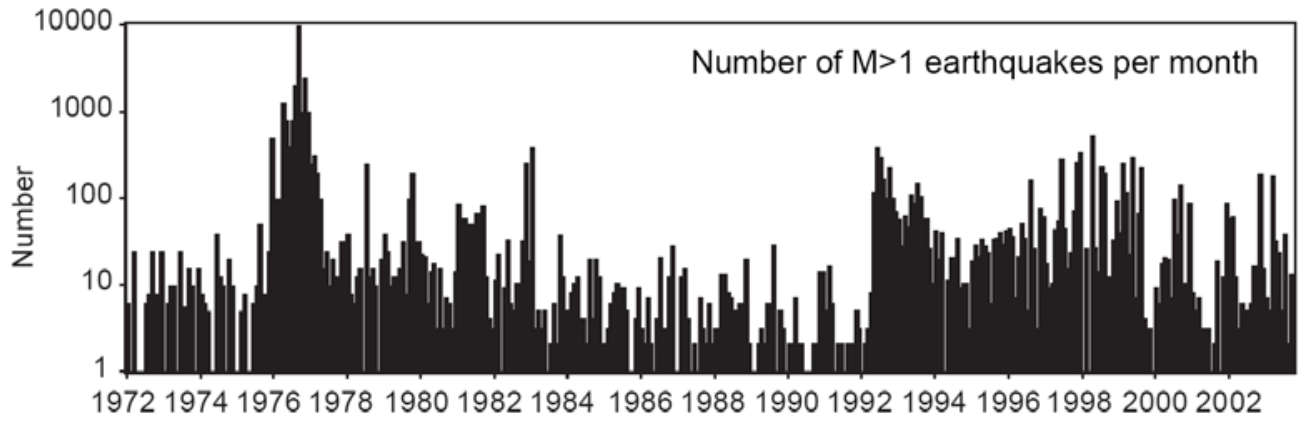

B

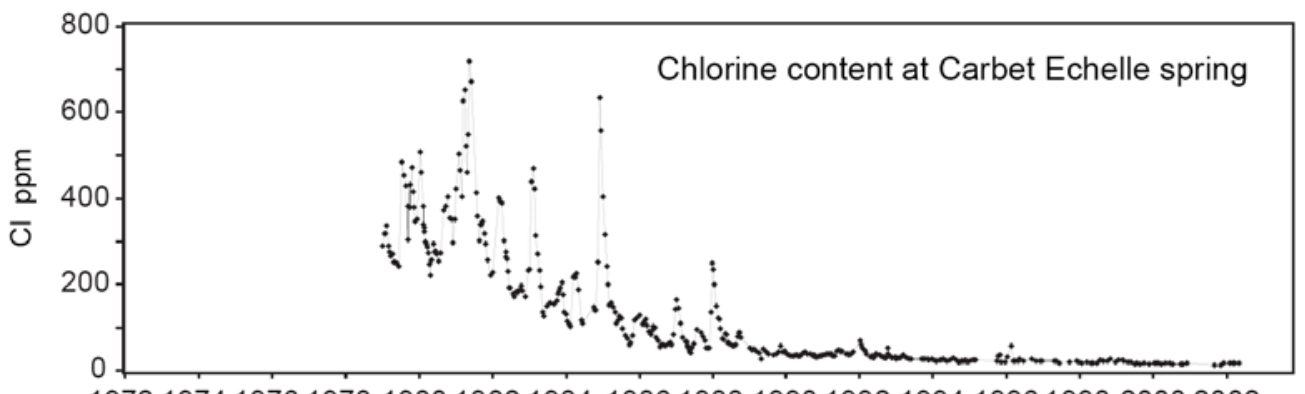

1972197419761978198019821984198619881990199219941996199820002002

Fig. 2. A) Number of seismic events per month (logarithmic scale) recorded at La Soufrière since Jan. 1974 until Sept. 2003 (only earthquakes with a magnitude N1) (Rapport de l'Observatoire Volcanologique et Sismologique de Guadeloupe, 1976-2006). It illustrates a long-term trend, decreasing until 1990-92, but punctuated by peaks of activity. Note the reactivation of the seismic activity in 1992. B) Chlorine content (ppm) of the water collected at Carbet Échelle thermal spring since Jan. 1979 (first sampling) until Sept. 2003, showing a remarkable episodicity. Note an uncertainty of $\pm 10 \mathrm{ppm}$ on $\mathrm{Cl}$ measurements performed using specific ion electrodes. 


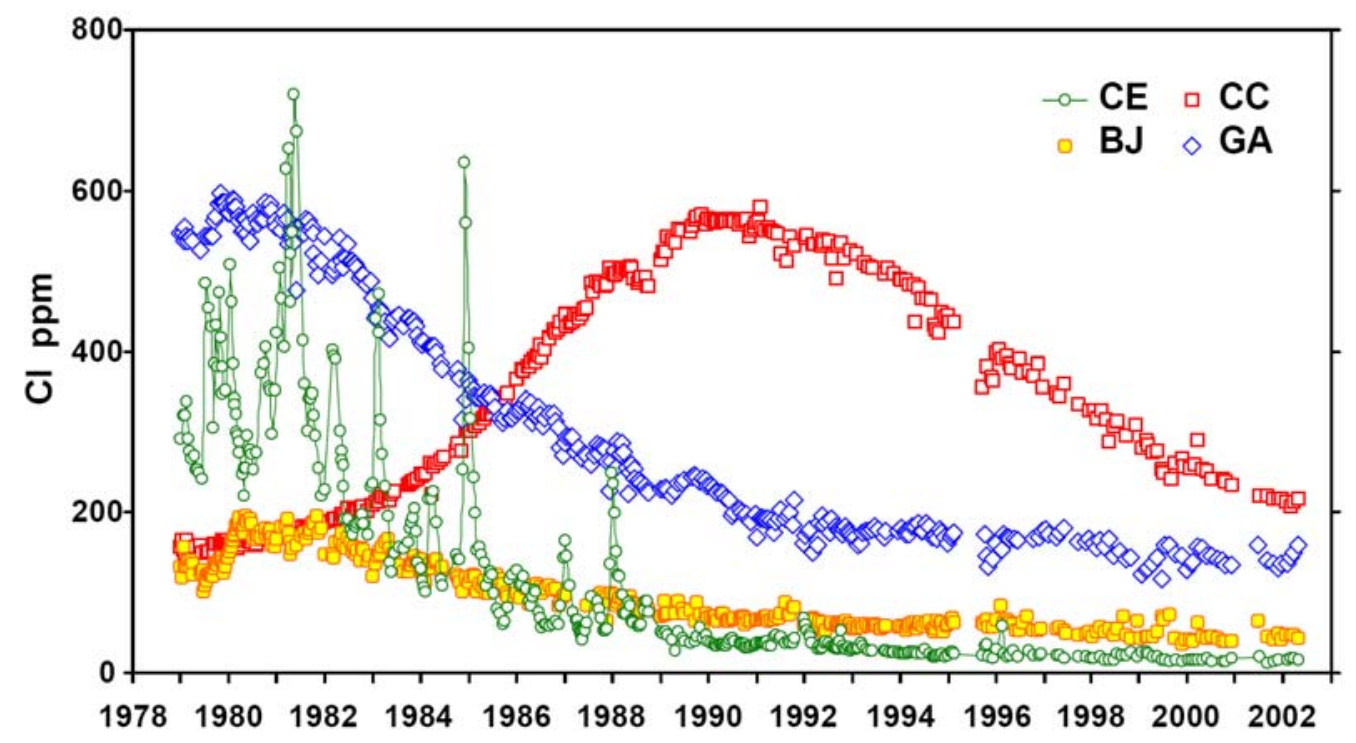

Fig. 3. Chlorine content in the water of La Soufrière's thermal springs contaminated by fluids of magmatic origin, including Carbet Échelle (CE), Galion (GA), Bains Jaunes (BJ) and Chutes du Carbet (CC) (Figure modified from Villemant et al. (2005). 


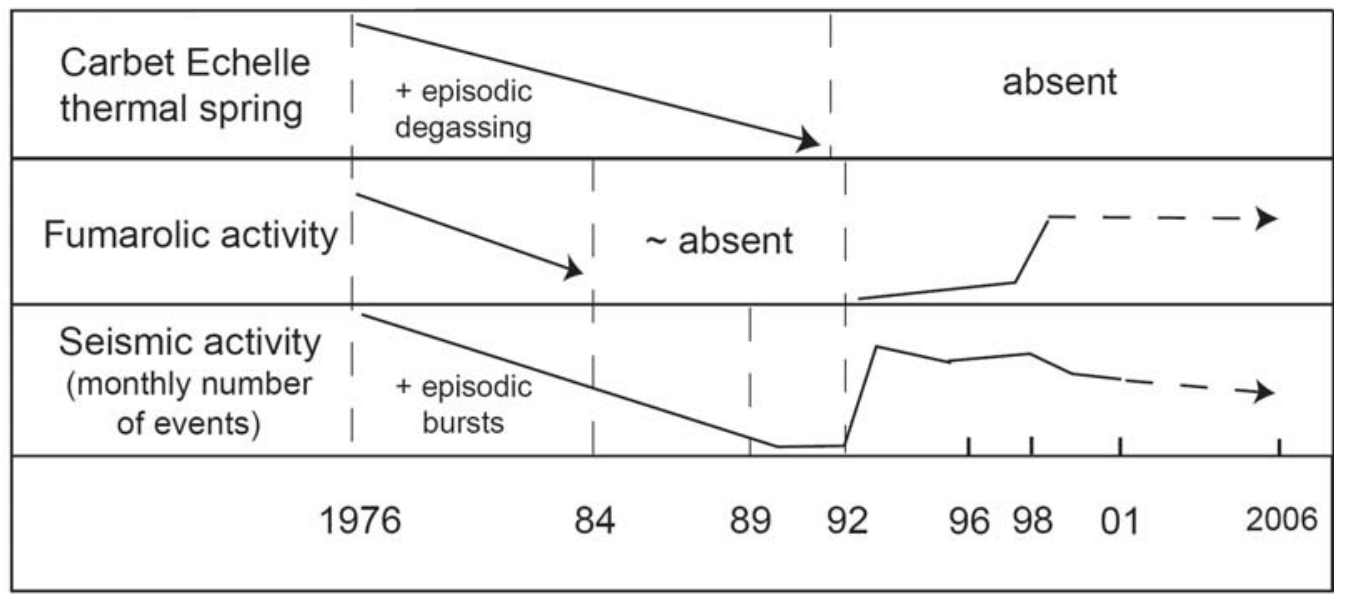

Fig. 4. Schematic illustration of the evolution since 1976 at La Soufrière of seismicity (described by the monthly number of earthquakes) and degassing, observed in the halogen content of Carbet Échelle thermal spring water and the fumarolic activity. 

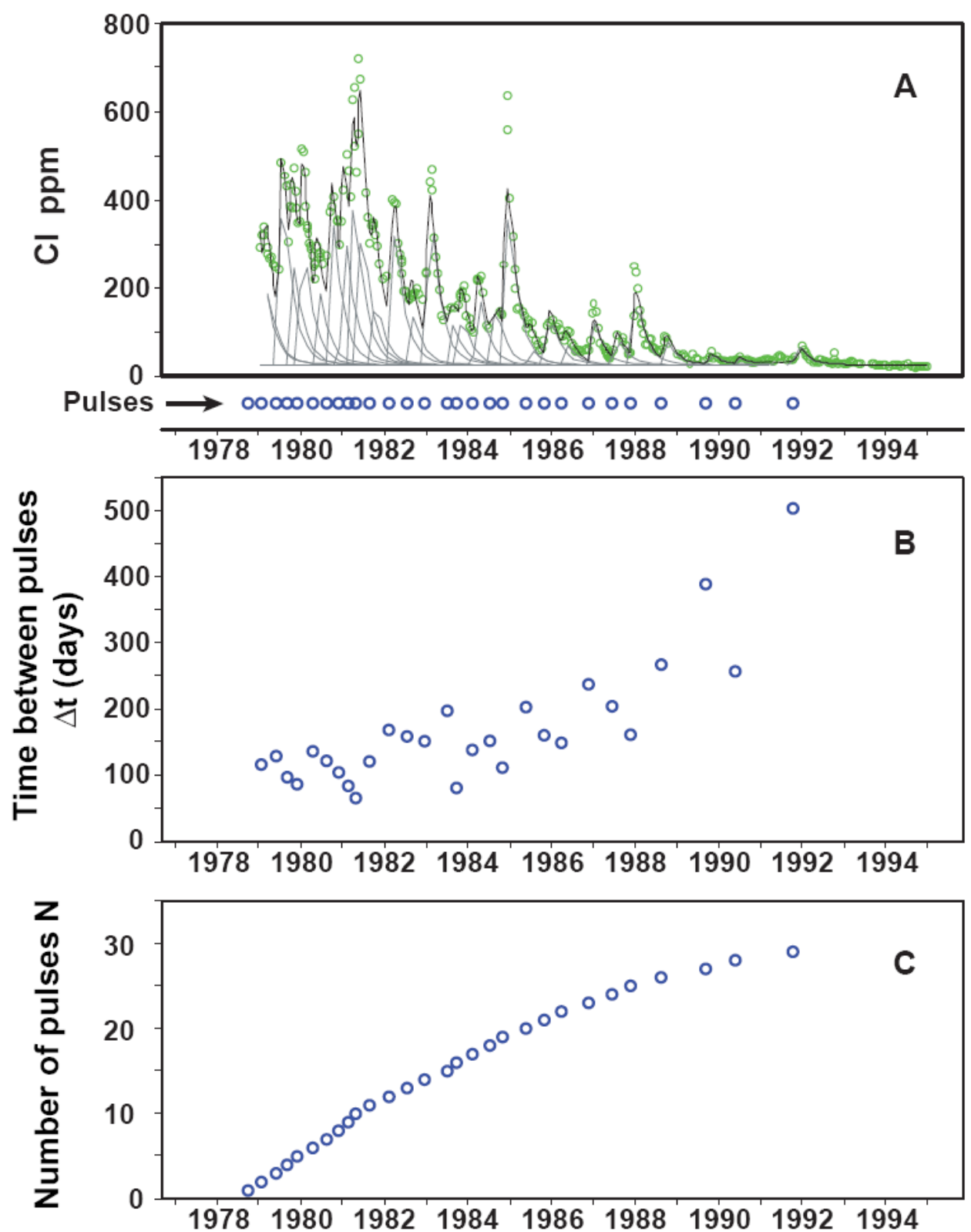

Fig. 5. Characteristics of the episodic $\mathrm{Cl}$ degassing released into the hydrothermal system of La Soufrière. (A) Timeseries of modeled $\mathrm{Cl}$ pulses (blue dots) injected into La Soufrière's hydrothermal system fitted to the time evolution of the $\mathrm{Cl}$ content of thermal springs contaminated by magmatic fluids, using advection-dispersion by water flow in a porous medium (from Villemant et al. (2005)). Gray lines represent advected and dispersed pulses providing the best fit of Carbet Échelle $\mathrm{Cl}$ content, considering a path length from the point of injection to that spring of $86 \mathrm{~m}$, a constant normalized flow rate value $\mathrm{U} / \omega \mathrm{R}$ fixed to $10^{-5}$ (with $\mathrm{U}$ the water flow velocity, $\omega$ the kinematic porosity and $\mathrm{R}$ the retardation factor) and a dispersion-related coefficient $\alpha$ of $28 \mathrm{~m}$ assuming the coefficient of dispersion along the flow direction equal to $\alpha \mathrm{U}$. The black line (best fit) is generated by the summation of this series of pulses in addition to a constant background taken equal to $25 \mathrm{ppm}$, corresponding to the $\mathrm{Cl}$ content recorded from 1979 in springs not contaminated by magmatic $\mathrm{Cl}$ inputs during the crisis (e.g. Bains Chauds du Matouba and Habitation Revel springs).(B) Evolution of the time interval $\mathrm{t}$ between consecutive $\mathrm{Cl}$ pulses injected into the hydrothermal system with sampling date. (C) Evolution of the number of $\mathrm{Cl}$ pulses since the first water sampling (5 Jan 1979). 
A. Initial state (water saturated magma)

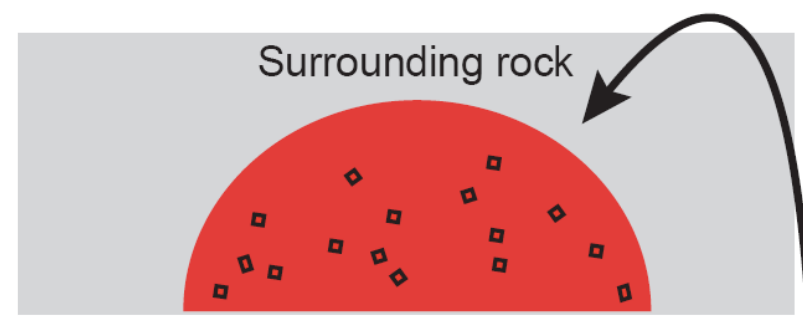

Magma intrusion
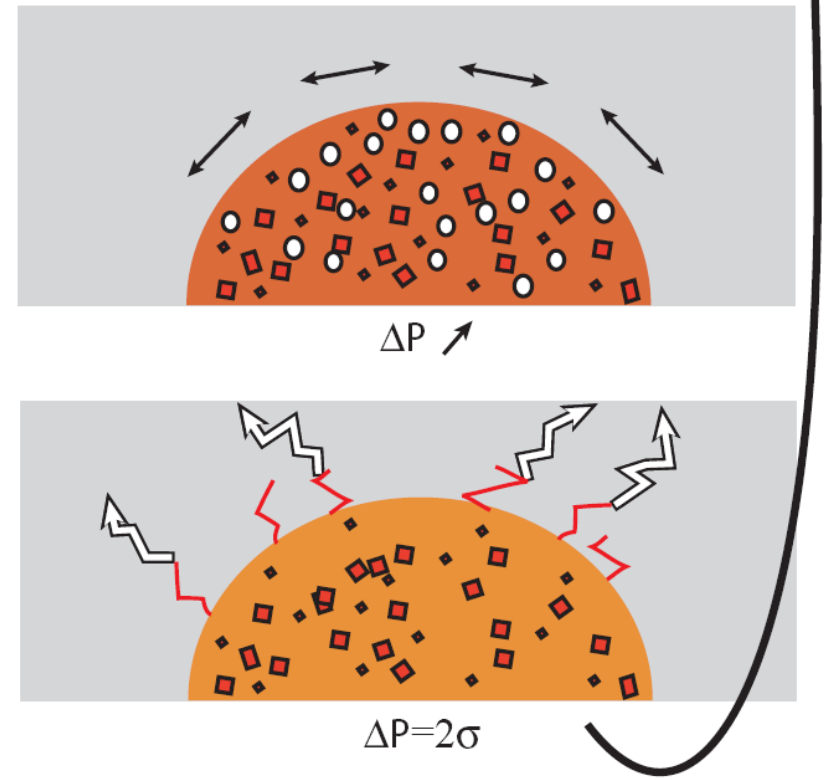

Fig. 6. Cartoon illustrating the model for episodic degassing of an andesitic magma intrusion developed by Boichu et al. (2008). 
Fig. 7. Comparison between data (circles) and model (crosses) of the evolution of: (Upper panel) the time interval $t$ between consecutive $\mathrm{Cl}$ pulses and (Lower panel) the number of pulses N over 30 years, since 1 July 1976 (assumed date of magma intrusion). Circles refer to raw data for the number of pulses estimated since the first water sampling in January 1979. Squares represent the extrapolated evolution of $\mathrm{N}$ since magma intrusion, supposing a regular appearance of pulses starting at the time of magma emplacement at shallow depth which is assumed on 1 July 1976. Each step in the modeled evolution of $\mathrm{N}$ corresponds to a pulse. The best model fit to data (red) is obtained for $\mathrm{R}=320 \mathrm{~m}$ and $\sigma=0.3 \mathrm{MPa}$, with secondary model parameters fixed to $\mathrm{z}=3 \mathrm{~km}, \Phi_{\mathrm{i}}=0.4 \mathrm{vol} . \%$ and $\Delta \mathrm{T}=400 \mathrm{~K}$. The range of $\sigma$ values, in $0.1-0.6 \mathrm{MPa}$, which brackets the evolution of the time interval $\Delta \mathrm{t}$ is shown in green.
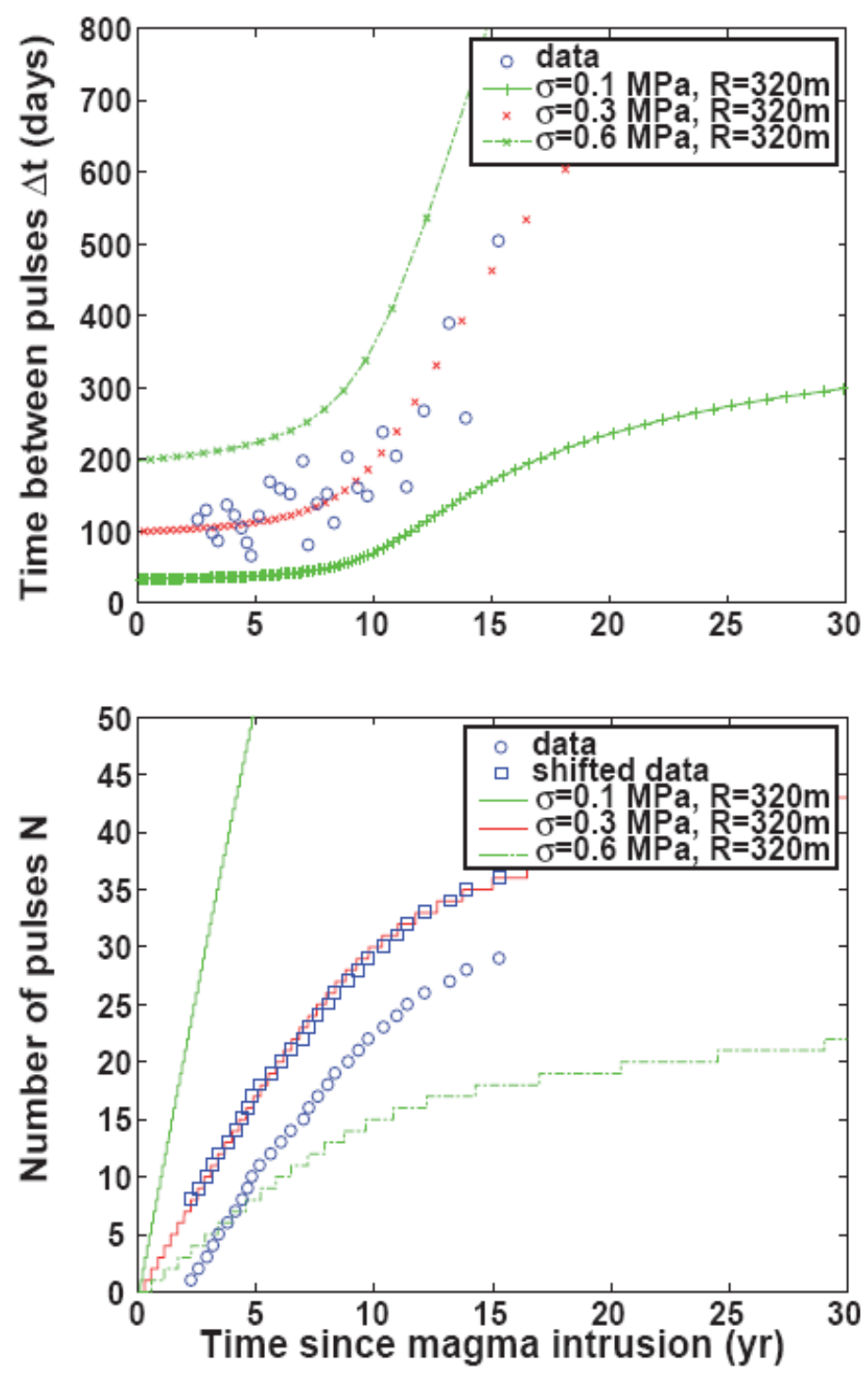

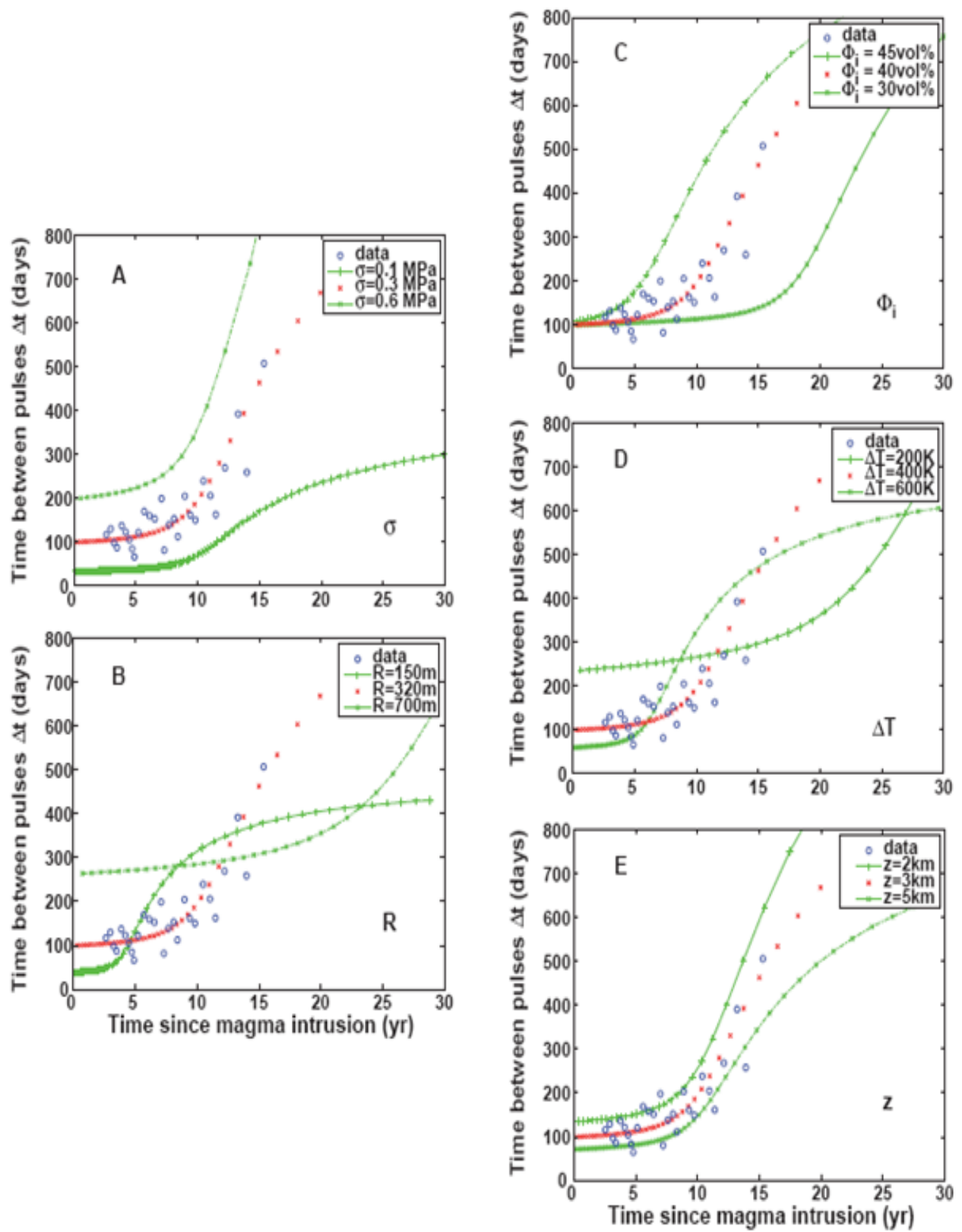

Fig. 8. Model sensitivity to main input parameters $\left(\sigma, \mathrm{R}, \Phi_{\mathrm{i}}, \Delta \mathrm{T}\right.$, and $\left.\mathrm{z}\right)$ is explored through variations in the temporal evolution of the time interval $\mathrm{t}$ between consecutive $\mathrm{Cl}$ pulses. We vary the value of one of the model inputs while holding the others fixed, at a mid-range value for secondary parameters $\left(\Phi_{\mathrm{i}}=40 \mathrm{vol} \%, \Delta \mathrm{T}=400 \mathrm{~K}, \mathrm{z}=3 \mathrm{~km}\right)$ and at the value associated to the best model fit for $\mathrm{R}(320 \mathrm{~m})$ and $\sigma(0.3 \mathrm{MPa})$ (see Section 3.2 for details concerning the choice of these values). Modeled time interval between pulses (green) with (A) $\sigma$ varying in the range $0.1-0.6 \mathrm{MPa}$, (B) $\mathrm{R}$ in $150-$ $700 \mathrm{~m},(\mathrm{C}) \Phi_{\mathrm{i}}$ in $30-45 \mathrm{vol} . \%$, (D) $\Delta \mathrm{T}$ in $200-600 \mathrm{~K}$, (E) $\mathrm{z}$ in $2-5 \mathrm{~km}$. Circles represent data and red crosses the best model fit todata (see Fig. 7 for details). 

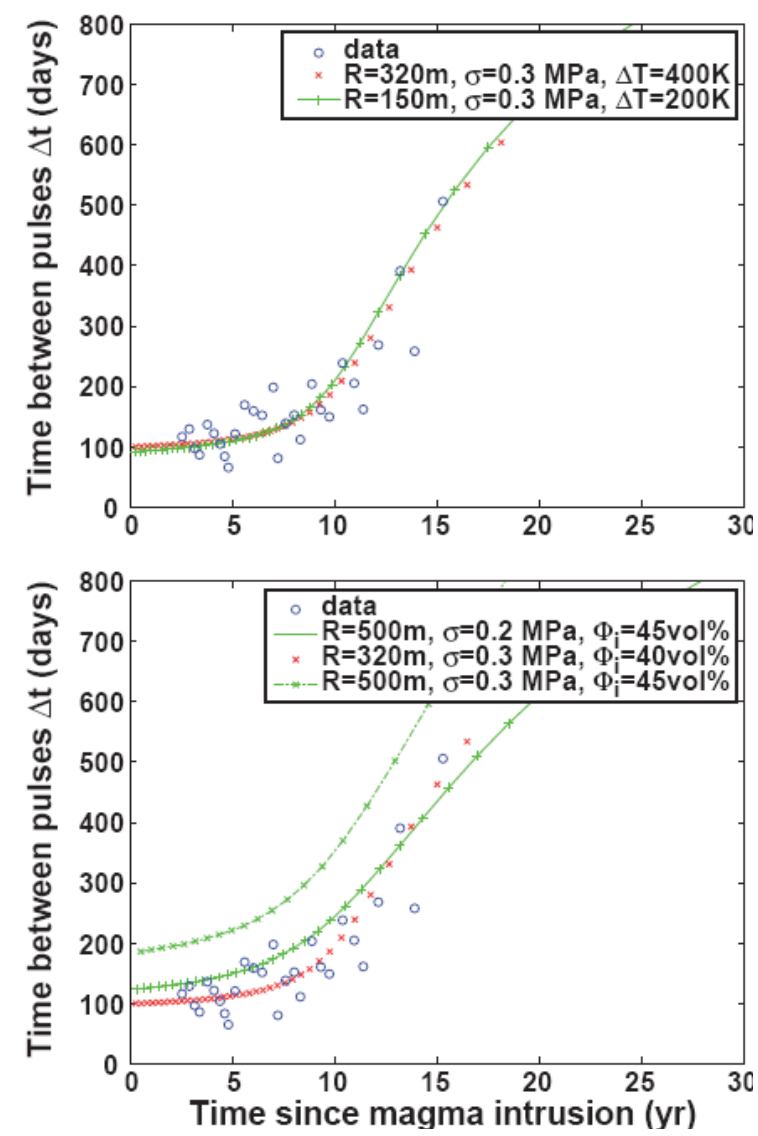

Fig. 9. Uncertainty on the value of the magma intrusion radius (R) deduced from model sensitivity to secondary input parameters. The modeled time interval $\Delta \mathrm{t}$ between $\mathrm{Cl}$ pulses (green) which allows a good fit to data (circles) is represented when: (Upper panel) the initial contrast of temperature $\Delta \mathrm{T}$ between magma and surrounding rocks is set to its lower value $(200 \mathrm{~K})$ - imposing the longest delay ( 20 years after magma intrusion) before transition to the second regime of degassing when $\mathrm{R}$ is fixed to its best fit value (Fig. 7) - which constrains the lower bound of $\mathrm{R}$ range to 150 $\mathrm{m}$; (Lower panel) the initial magma crystal content $\Phi_{\mathrm{i}}$ is set to its upper value (45 vol.\%) - imposing the earliest date ( 4 years) for transition between degassing modes (Fig. 7) - which constrains the upper bound of R range to $500 \mathrm{~m}$. $\sigma$ and $z$, which have a negligible impact on the time of change in degassing regime, are respectively fixed to $0.3 \mathrm{MPa}$ and $3 \mathrm{~km} . \Phi_{\mathrm{i}}$ and $\Delta \mathrm{T}$, when not varied, are fixed to their mid-range value of $40 \mathrm{vol} . \%$ and $400 \mathrm{~K}$. Red crosses represent the
best
model
fit
to
data
(see
Fig.
7
for
details). 


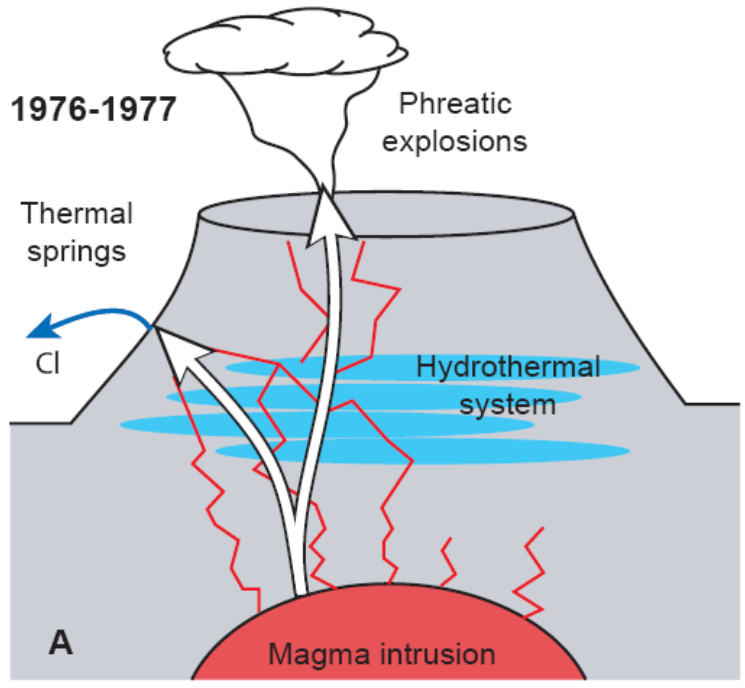

pre-1992

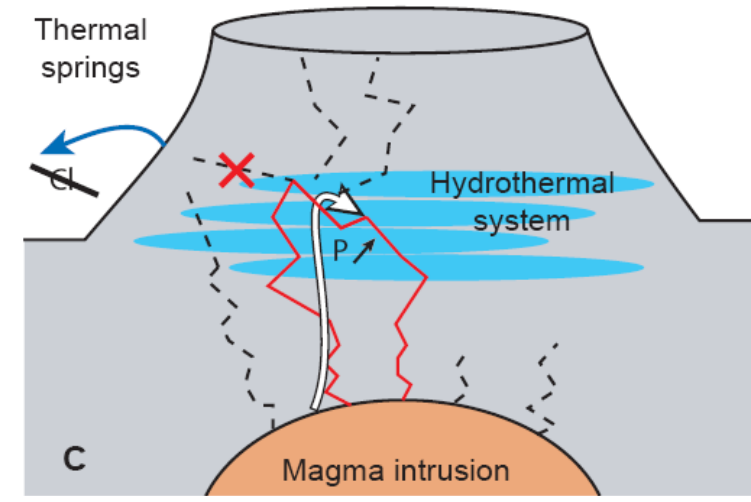

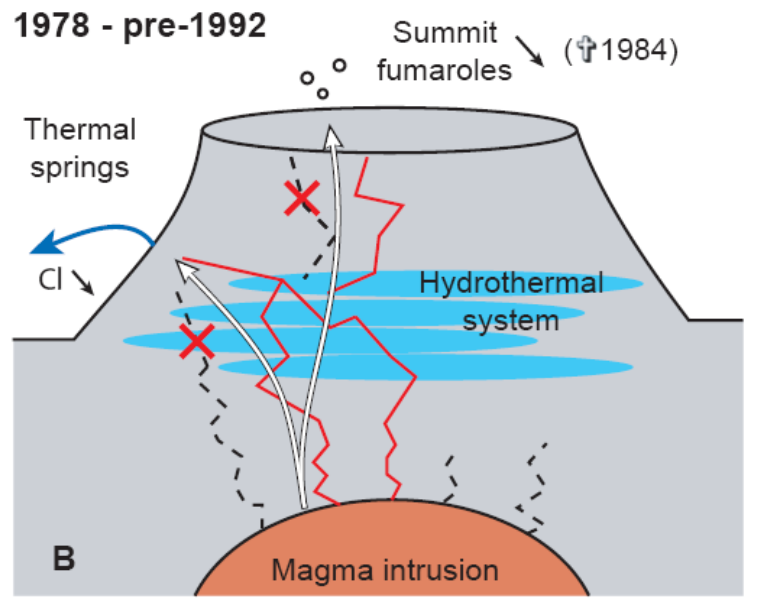

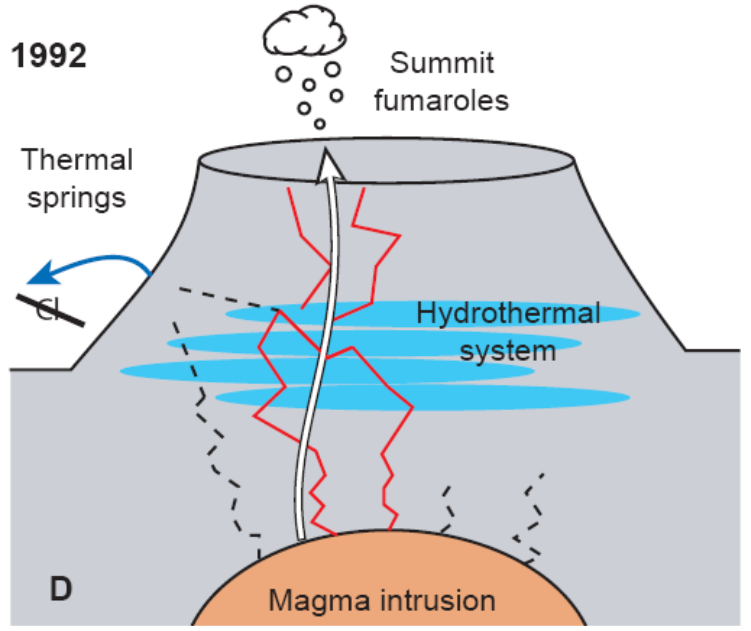

Fig. 10. Cartoon illustrating an interpretation of La Soufrière activity from the last 1976 crisis until 1992 (see Section 4.2 for details). 